\title{
Analyzing Ecological Systems Using Network Analysis
}

\author{
*,**,***Bian D. Fath
}

\author{
${ }^{*}$ Biology Department, Towson University, Towson, Maryland, USA \\ ${ }^{* *}$ Fulbright Distinguished Chair in Energy and Environment, Parthenope University of Naples, Italy \\ ***Advanced Systems Analysis Program, International Institute for Applied Systems Analysis, Austria, \\ e-mail:bfath@towson.edu
}

\begin{abstract}
Network Environ Analysis, based on network theory, reveals the quantitative and qualitative relations between ecological objects interacting with each other in a system. The primary result from the method provides input and output "environs", which are internal partitions of the objects within system flows. In addition, application of Network Environ Analysis on empirical datasets and ecosystem models has revealed several important and non-intuitive results that have been identified and summarized in the literature as network environ properties. Network Environ Analysis requires data including the inter-compartmental flows, compartmental storages, and boundary input and output flows. Software is available to perform this analysis on the collected data. This article reviews the theoretical underpinning of the analysis and briefly introduces some the main properties such as indirect effects ratio, network homogenization, and network mutualism.
\end{abstract}

Key words: boundary conditions, connectivity, energy flows, environment, indirect effects, mutualism, network analysis, systems ecology.

\section{Introduction}

The natural world is interconnected: nothing persists in isolation. The survival of any organism is its ability to contribute to and fit into a larger network of ecosystem interactions. The question remains how to study an individual without needing to also carry back into the "infinite regress" (Mason \& Langenheim 1957) of indirect and distal entities and causes. Succinctly put: "How can we know anything, if everything is connected to everything else?" That is the ecological question addressed in this paper.

Previous papers in this journal have addressed the network issue, but from a connectivity perspective (Ulrich 2009) or from an information theory perspective (Ulanowicz 2004). Other approaches to ecological network analysis have been published elsewhere such as investigation of food webs (Dunne et al. 2002, 2004; Christian \& Luczkovich 1999), pollination networks (Bascompte et al. 2003; Olesen et al. 2007), and keystone species (Jordan 2009;
Jordan et al. 2009; Ortiz et al. 2013) to mention a few. Here, I provide an overview of flow-based network methodology called Environ Analysis (Patten 1978) with sample applications.

When answering the question about how everything is connected, one approach has been to apply reductionism and focus downward and inward on the individual itself. This allows one to learn much detail of the single object but at the expense of the larger forces which affect it. The next step upward and outward includes the direct, but only direct, influences which impact the focal entity (Maelzer 1965). This incorporates the environment in terms of inputs and outputs to the organism, but truncates anything beyond first order interactions; thus, removing any indirect, historical, or cyclical feedback. These answers, in other words, strive to know something by not considering how it is connected to everything else. This, of course, is an unsatisfactory resolution, but without a more comprehensive theory and rigorous methodology was standard sci- 
entific practice. One result of reductionism was the regular unintended consequences, often in terms of environmental degradation, emanating from not seeing the big picture.

The question of the system boundary becomes central, because if we can extend the boundary from the individual to a system in which the organism resides, then we can know how the "within system boundary" interactions contribute to and influence the entity of interest. In fact, we can know how all entities influence and are influenced by the other entities. An approach to do just that was introduced in a paper by Patten (1978). The within system boundary are known as the environs of each entity occurring dually in input and output orientation. The influence of internal interactions can be completely revealed using network environ analysis. This in turn pushes the question to a higher scale, and outside the system boundary it is still unresolved. But, the shift upward provides a system-oriented analysis tool that allows one to address the question of how we can understand connected systems. The basics of this approach are described below.

\section{Theoretical Development of Environ Analysis}

In order to study environment as a formal object, a system boundary is a necessary condition to avoid the issue of infinite regress, because in principle one could trace the environment of each object back in history. The realization of a boundary is, in fact, one of the three foundational principles in Patten's (1978) seminal paper introducing the environ theory concept. The necessary boundary demarcates two environments, the unbound external environment, which indeed includes all space-time objects in the universe, and the second internal one, containing the within system boundary compartments of interest. This quantifiable, internal environment for each system object is termed "environ", and is the study of Environ Analysis. An object's environ stops at the system boundary, but as ecosystems are open systems, they require exchanges across the boundary into and out of the system. Therefore, input and output boundary flows are necessary to maintain the system's far-from-equilibrium organization. Objects and connections that reside wholly in the external environment are not germane to the analysis.

Another foundational principle of environ analysis theory is that each object in the system itself has two "environs" one receiving and one generating flows in the system. In other words, an object's input environ includes those flows from within the system boundary leading up to the object, and an output environ, those flows emanating from the object back to the other system objects before exiting the system boundary (Patten 1981, 1982; Bata et al. 2007). This alters the perception from internal-external to receiv- ing-generating. Thus, the object, while distinct in time and space, is more clearly embedded in and responsive to the couplings with other objects within the network. This shifts the focus from the objects themselves to the relations they maintain; or from parts to processes - what Ilya Prigogine called from "Being to Becoming" (Prigogine 1980).

The third foundational principle of Network Environ Analysis is that individual environs (and the flow carried within each one) are unique such that the system comprises the set union of all environs, which in turn partition the system level of organization. This partitioning allows one to classify environ flow into what have been called different modes: mode 0 ) boundary input; 1) first passage flow received by an object from other objects in the system (i.e., not boundary flow), but also not cycled flow (in other words first time flow reaches an object); 2) cycled flow that returns to a compartment before leaving the system; 3) dissipative flow in that it has left the focal object not to return, but does not directly cross a system boundary (i.e., it flows to another within system object); and 4) boundary out (Higashi et al. 1993). The modes have been used to understand better the general role of cycling and the flow contributions from each object to the other, which has had application in showing a complementarity of several of the holistic, thermodynamic-based ecological indicators (see Fath et al. 2001).

\subsection{Holistic Reductionism}

Environ Analysis is in a more general class of methods called Ecological Network Analysis (ENA) which uses network theory to study the interactions between organisms or populations within their environment. Bernard Patten was the originator of the environ analysis approach in the late 1970s and along with his colleagues have expanded the analysis to reveal many insightful, holistic properties of ecosystem organization (Patten 1978, 1981, 1982, 1991; Dame \& Patten 1981; Fath \& Patten 1998, 1999a; Kazanci 2007). ENA follows along the synecology perspective introduced by EP Odum (1953) which is mostly concerned with interrelations of material, energy and information among system components (Table 1).

Table 1. Two main paradigms used for ecological investigations

\begin{tabular}{|l|l|}
\hline Synecology & Autecology \\
\hline Holistic & Reductionistic \\
\hline $\begin{array}{l}\text { Ecology of relationships } \\
\text { among the various organisms } \\
\text { and populations }\end{array}$ & $\begin{array}{l}\text { Ecology of individual } \\
\text { organisms and populations }\end{array}$ \\
\hline $\begin{array}{l}\text { Mostly concerned with } \\
\text { communication of material, } \\
\text { energy and information } \\
\text { among system components }\end{array}$ & $\begin{array}{l}\text { Mostly concerned with the } \\
\text { elements themselves }\end{array}$ \\
\hline
\end{tabular}


ENA starts with the assumption that a system can be represented as a network of nodes (compartments, objects, etc.) and the connections between them (links, flows, etc.). In ecological systems, the connections are usually based on the flow of energy, matter, or nutrients between the system compartments. If such a flow exists, then there is a direct transaction between the two connected compartments. These direct transactions give rise to both direct and indirect relations between all the objects in the system. Network analysis provides a systems-oriented perspective as it is based on uncovering patterns and relations among all the objects in a system.

On one level network Environ Analysis could be referred to as an holistic-reductionistic approach. It is holistic because it considers simultaneously the whole influence of all system objects, yet it is reductionistic in that the fine details of all object transactions are entailed in the analysis. The network data requirements include the complete flow-storage quantities for each identified link and node (note flow and storage are interchangeable as determined by the turnover rate). Data can be acquired from empirical observations, literature estimates, model simulation results, or balancing procedures, when all but a few are unknown. This difficulty in obtaining data has resulted in a dearth of available complete network datasets. Due to this lack of requisite data for fully quantified food webs, researchers have developed community assembly rules that are heuristics to construct ecological food webs. Assembly rules are in general a set of rules that will generate a connectance matrix for a number of $\mathrm{N}$ species. Common assembly rules that have been developed are random or constant connectance, cascade, niche, modified niche, and cyber-ecosystem each with its own assumptions and limitations (see Halnes et al. 2007). In all but the last case, the assembly rules construct only the structural food web topology. The cyber-ecosystem methodology also includes a procedure for quantifying the flows along each link. It uses a meta-structure of six functional groups: Producer (P), Herbivore $(\mathrm{H})$, Carnivore (C), Omnivore (O), Detritus (D), and Detrital Feeders (F), within which random connections link species based on these definitional constraints.

\section{Case Study: Cone Spring Ecosystem Network}

To demonstrate basic Environ Analysis, a commonly studied ecosystem network model first proposed by Tilly (1968) is used as an example. Figure 1 shows the network structure and includes the storages and flow values between

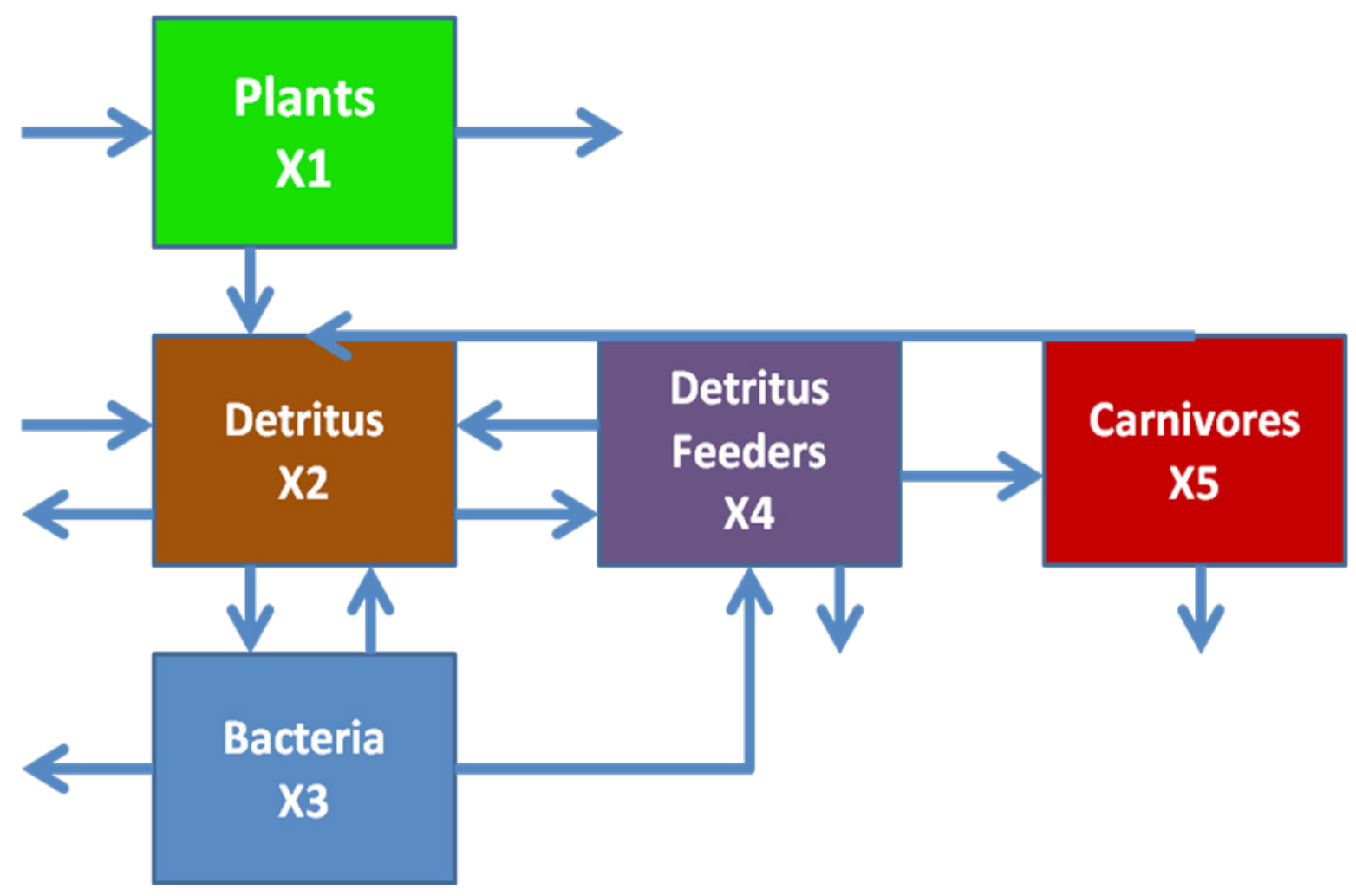

Figure 1. Cone Spring Network Model (Finn 1976 after Tilley 1968); Five compartment model used to demonstrate Environ Analysis notation and methodology 
Table 2. Basic methodologies for Network Environ Analysis

\begin{tabular}{|l|l|}
\hline STRUCTURAL ANALYSIS & FUNCTIONAL ANALYSES \\
\hline \multirow{3}{*}{$\begin{array}{l}\text { Path Analysis } \\
\text { enumerates pathways in a network } \\
\text { (connectance, cyclicity, etc.) }\end{array}$} & $\begin{array}{l}\text { Flow Analysis: } \mathrm{g}_{\mathrm{ij}}=\mathrm{f}_{\mathrm{ij}} / \mathrm{T}_{\mathrm{j}} \\
\text { Identifies flow intensities along indirect pathways }\end{array}$ \\
\cline { 2 - 2 } & $\begin{array}{l}\text { Storage Analysis: } \mathrm{c}_{\mathrm{ij}}=\mathrm{f}_{\mathrm{ij}} / \mathrm{x}_{\mathrm{j}} \\
\text { Identifies storage intensities along indirect pathways }\end{array}$ \\
\cline { 2 - 2 } & $\begin{array}{l}\text { Utility Analysis: } \mathrm{d}_{\mathrm{ij}}=\left(\mathrm{f}_{\mathrm{ij}}-\mathrm{f}_{\mathrm{ji}}\right) / \mathrm{T}_{\mathrm{i}} \\
\text { Identifies utility intensities along indirect pathways }\end{array}$ \\
\hline
\end{tabular}

compartments. The network has 5 compartments or nodes $\left(\mathrm{x}_{\mathrm{i}}\right.$, for $\mathrm{i}=1$ to 5$)$ representing: $\mathrm{X} 1$ ) Plants, $\mathrm{X} 2$ ) Detritus, X3) Bacteria, X4) Detritus Feeders, and X5) Carnivores, respectively. Compartments are connected by transaction of the energy flows between them. These pair-wise couplings are the basis for the internal network structure.

This basic information regarding the storages, flows, and boundary flows provides all the necessary information to conduct Environ Analysis. Environ Analysis has been classified into a structural analysis - dealing only with the network topology, and three functional analyses-flow, storage, and utility - which require the numerical values for flow and storage in the network (Table 2).

\subsection{Structural Analysis}

A structural connectance matrix, or adjacency matrix, $\mathbf{A}$, is a binary representation of the connections such that $\mathrm{a}_{\mathrm{ij}}=1$ if there is a connection from $\mathrm{j}$ to $\mathrm{i}$, and a zero otherwise (Eq 1).

$$
A=\left[\begin{array}{lllll}
0 & 0 & 0 & 0 & 0 \\
1 & 0 & 1 & 1 & 1 \\
0 & 1 & 0 & 0 & 0 \\
0 & 1 & 1 & 0 & 0 \\
0 & 0 & 0 & 1 & 0
\end{array}\right]
$$

Using this adjacency matrix one can calculate the number of pathways between compartments along paths of various lengths, in that the power of the matrix is equivalent to the path length. For example, the $\mathrm{A}^{2}$ matrix below shows that there is exactly one path of length two from X1 to X5 and zeros paths of length two from X1 to X6, etc. A few powers are given below for inspection. Note, that while taking longer path sequences the numbers of path connections between compartments increases in well connected networks (except row 1 remains zero since there are no return paths to the $\mathrm{X} 1$ ). In fact, they grow so rapidly (note, by the time we look at $\mathrm{A}^{20}$ there are over 78,000 unique paths between nodes X2 and X3!) that it is this abundance of pathways that give rise to the important contribution of indirect influence described below in the functional properties.

$$
\begin{aligned}
A^{2} & =\left[\begin{array}{lllll}
0 & 0 & 0 & 0 & 0 \\
0 & 2 & 1 & 1 & 0 \\
1 & 0 & 1 & 1 & 1 \\
1 & 1 & 1 & 1 & 1 \\
0 & 1 & 1 & 0 & 0
\end{array}\right] A^{3}=\left[\begin{array}{lllll}
0 & 0 & 0 & 0 & 0 \\
2 & 2 & 3 & 2 & 2 \\
0 & 2 & 1 & 1 & 0 \\
1 & 2 & 2 & 2 & 1 \\
1 & 1 & 1 & 1 & 1
\end{array}\right] \\
A^{4} & =\left[\begin{array}{lllll}
0 & 0 & 0 & 0 & 0 \\
2 & 5 & 4 & 4 & 2 \\
2 & 2 & 3 & 2 & 2 \\
2 & 4 & 4 & 3 & 2 \\
1 & 2 & 2 & 2 & 1
\end{array}\right] A^{5}=\left[\begin{array}{lllll}
0 & 0 & 0 & 0 & 0 \\
5 & 8 & 9 & 7 & 5 \\
2 & 5 & 4 & 4 & 2 \\
4 & 7 & 7 & 6 & 4 \\
2 & 4 & 4 & 3 & 2
\end{array}\right]
\end{aligned}
$$

$$
A^{10}=\left[\begin{array}{ccccc}
0 & 0 & 0 & 0 & 0 \\
96 & 178 & 177 & 149 & 96 \\
53 & 96 & 97 & 81 & 53 \\
81 & 149 & 149 & 125 & 81 \\
44 & 81 & 81 & 68 & 44
\end{array}\right]
$$

$A^{20}=\left[\begin{array}{ccccc}0 & 0 & 0 & 0 & 0 \\ 42762 & 78653 & 78652 & 66012 & 42762 \\ 23250 & 42762 & 42763 & 35890 & 23250 \\ 35890 & 66012 & 66012 & 55403 & 35890 \\ 19513 & 35890 & 35890 & 30122 & 19513\end{array}\right]$


There are many structural properties of the network which can be determined from this analysis. Table 3 provides a few for Cone Spring ecosystem such as connectance, link density, in-degree, out-degree, and path proliferation (the rate of increase in number of paths).

Table 3. Structural network properties

\begin{tabular}{|l|l|}
\hline Structural property & Value \\
\hline$\#$ links & 8 \\
\hline Connectance & 0.32 \\
\hline Link density & 1.6 \\
\hline In-degree (row sum) & {$\left[\begin{array}{llll}0 & 4 & 1 & 2\end{array}\right]$} \\
\hline Out-degree (column sum) & {$\left[\begin{array}{llll}1 & 2 & 2 & 2\end{array}\right]$} \\
\hline Path proliferation & 1.84 \\
\hline
\end{tabular}

\subsection{Functional Analysis}

Storage and flows must have consistent units (although it is possible to consider multi-unit networks). Typically, units for storages are given in the amount of energy or biomass per given area or volume (e.g., g/ $\mathrm{m}^{2}$ ), and units for flows are the same but as a rate (e.g., $\mathrm{g} /\left(\mathrm{m}^{2 *}\right.$ day $\left.)\right)$. The generic intercompartmental flows for Figure 1 are given in the following flow matrix, $\mathbf{F}$ :

$$
F=\left[\begin{array}{ccccc}
0 & 0 & 0 & 0 & 0 \\
f_{21} & 0 & f_{23} & f_{24} & f_{25} \\
0 & f_{32} & 0 & 0 & 0 \\
0 & f_{42} & f_{43} & 0 & 0 \\
0 & 0 & 0 & f_{54} & 0
\end{array}\right]
$$

which for this specific example becomes:

$$
F=\left[\begin{array}{ccccc}
0 & 0 & 0 & 0 & 0 \\
8881 & 0 & 1600 & 200 & 167 \\
0 & 5204 & 0 & 0 & 0 \\
0 & 2309 & 75.1 & 0 & 0 \\
0 & 0 & 0 & 370.1 & 0
\end{array}\right]
$$

Note the orientation of flow from $j$ to $i$ is used because that makes the direction of ecological relation from $i$ to $j$. For example, if $i$ preys on $j$, the flow of energy is from $j$ to i. All compartments experience dissipative flow losses $\left(y_{i}\right.$, for $i=1$ to 5$)$, and here the first compartment receives external flow input, $\mathrm{z}_{1}$, (arrows starting or ending not on another compartment represent boundary flows). For this example, these can be given as:

$y=\left[\begin{array}{lllll}y_{1} & y_{2} & y_{3} & y_{4} & y_{5}\end{array}\right]$

and $z=\left[\begin{array}{c}z_{1} \\ z_{2} \\ 0 \\ 0 \\ 0\end{array}\right]$

which are, respectively:

$$
\begin{aligned}
& y=\left[\begin{array}{lllll}
2303 & 3969 & 3530 & 1814 & 203
\end{array}\right] \\
& z=\left[\begin{array}{c}
11184 \\
635 \\
0 \\
0 \\
0
\end{array}\right]
\end{aligned}
$$

Total throughflow of each compartment is an important variable, which is the sum of flows into, $T_{i}^{i n}=z_{i}+\sum_{j}^{n} f_{i j}$, or out of, $T_{i}^{\text {out }}=y_{i}+\sum_{j}^{n} f_{j i}$ the $\mathrm{i}^{\text {th }}$ compartment. At steady state, compartmental inflows and outflows are equal such that $\mathrm{dx}_{\mathrm{i}} / \mathrm{dt}=0$, and therefore, incoming and outgoing throughflows are equal also: $T_{i}^{\text {in }}=T_{i}^{\text {out }}=T_{i}$. In vector notation, compartmental throughflows are given by:

$T=\left[\begin{array}{c}T_{1} \\ T_{2} \\ T_{3} \\ T_{4} \\ T_{5}\end{array}\right]$

The sum of all throughflows is called Total System Throughflow (TST) and is an important measure of the total energy passing through the network. For Cone Spring ecosystem TST $=30626 \mathrm{kcal} \mathrm{m}^{-2} \mathrm{y}^{-1}$.

The technical aspects of environ analysis are explained in detail elsewhere (Patten 1981, 1982), so rather than repeat those here, the remainder of the entry highlights some of the important results from environ analysis. But first, one issue that must be covered is the way in which network analysis identifies and quantifies indirect pathways and flow contributions. Indirectness originates from trans- 
fers or interactions that occur non-directly, and are mediated by other within system compartments. These transfers could travel two, three, four, or many links before reaching the target destination. For example, the flow analysis starts with the calculation of the non-dimensional flow intensity matrix, $\mathbf{G}$, where $g_{\mathrm{ij}}=\mathrm{f}_{\mathrm{ij}} / \mathrm{T}_{\mathrm{j}}$. The $\mathbf{G}$ matrix corresponding to Figure 1 would look as follows:

$G=\left[\begin{array}{ccccc}0 & 0 & 0 & 0 & 0 \\ 0.7941 & 0 & 0.3074 & 0.0839 & 0.4514 \\ 0 & 0.4533 & 0 & 0 & 0 \\ 0 & 0.2011 & 0.0144 & 0 & 0 \\ 0 & 0 & 0 & 0.1552 & 0\end{array}\right]$

These values represent the fraction of flow along each link normalized by the total throughflow at the donating compartment. These elements give the direct, measurable flow intensities (or probabilities) between any two nodes $\mathrm{j}$ to $\mathrm{i}$. To identify the flow intensities along indirect paths (e.g., $\mathrm{j} \rightarrow \mathrm{k} \rightarrow \mathrm{i}$ ), one need only consider the matrix $\mathbf{G}$ raised to the power equal to the path length in question. For example, $\mathbf{G}^{2}$ gives the flow intensities along all paths of length 2, $\mathbf{G}^{3}$ along all paths of length 3, etc. This well-known matrix algebra result is the primary tool to uncover system indirectness. In fact, it turns out that due to the way in which the $\mathbf{G}$ matrix is constructed all elements in $\mathbf{G}^{\mathrm{m}}$ go to zero as $\mathrm{m} \rightarrow \infty$. Therefore, it is possible to sum the terms of $\mathbf{G}^{\mathrm{m}}$ to acquire an "integral" flow matrix (called $\mathbf{N}$ ), which gives the flow contribution from all path lengths.

$$
N=G^{0}+G^{1}+G^{2}+G^{3}+\ldots=\sum_{m=0}^{\infty} G^{m}=(I-G)^{-1}
$$

where $\mathbf{G}^{0}=\mathrm{I}$, the identity matrix, $\mathbf{G}^{1}$ the direct flows, and $\mathbf{G}^{\mathrm{m}}$ for $\mathrm{m}>1$ are all the indirect flows intensities. Note, that the elements of $\mathbf{G}$ and $\mathbf{N}$ are non-dimensional; to retrieve back the actual throughflows, one need only multiply the integral matrix by the input vector: $\mathrm{T}=\mathrm{Nz}$. In other words, $\mathrm{N}$ redistributes the input, $\mathrm{z}$, throughout each compartment to recover the total flow through that compartment. Similarly, one could acquire any of the direct or indirect flows by multiplying $\mathbf{G}^{\mathrm{m}} \mathbf{z}$ for any $\mathrm{m}$.

$$
N=\left[\begin{array}{ccccc}
1.0 & 0 & 0 & 0 & 0 \\
0.9582 & 1.2067 & 0.3736 & 0.1858 & 0.5446 \\
0.4343 & 0.5470 & 1.1694 & 0.0842 & 0.2469 \\
0.1989 & 0.2505 & 0.0920 & 1.0386 & 0.1131 \\
0.0309 & 0.0389 & 0.0143 & 0.1612 & 1.0175
\end{array}\right]
$$

A similar argument is made to develop integral storage and utility matrices.

$$
\begin{aligned}
& \text { storage: } Q=P^{0}+P^{1}+P^{2}+P^{3}+\ldots=\sum_{m=0}^{\infty} P^{m}=(I-P)^{-1} \\
& \text { utility: } U=D^{0}+D^{1}+D^{2}+D^{3}+\ldots=\sum_{m=0}^{\infty} D^{m}=(I-D)^{-1}
\end{aligned}
$$

where $\mathrm{p}_{\mathrm{ij}}=\left(\mathrm{f}_{\mathrm{ij}} / \mathrm{x}_{\mathrm{j}}\right) \Delta \mathrm{t}$, and $\mathrm{d}_{\mathrm{ij}}=\left(\mathrm{f}_{\mathrm{ij}}-\mathrm{f}_{\mathrm{ji}}\right) / \mathrm{T}_{\mathrm{i}}$.

\subsection{Network Properties}

Patten has developed a series of "ecological network properties" which summarize the results of environ analysis. These have all been described in the literature (for an overview of the 13 main ones, see Jørgensen et al. 2007, Chapter 5). The properties have been used to assess the current state of ecosystem networks and to compare the state of different networks. Furthermore, while interpreting some of the properties as ecological goal functions, it has been possible to identify the structural or parametric configurations that positively affect the network property values as a way to detect or anticipate network changes. For example, certain network alterations, such as increased cycling, lead to greater total system energy throughflow and energy storage, so one could expect that, if possible, ecological networks are evolving or adapting to such configurations. This leads to a new area of research on evolving networks. In this section, a brief overview is given for four of these properties: dominance of indirect effects (or non-locality), network homogenization, network mutualism, and environs themselves.

\subsubsection{Dominance of indirect effects}

This property compares the contribution of flow along indirect pathways with those along direct ones (see Higashi \& Patten 1986, 1989; Whipple \& Patten 1993). Indirect effects are any that require an intermediary node to mediate the transfer and can be of any length. The strength of indirectness has been measured in a ratio of the sum of the indirect flows intensities divided by the direct flow intensities:

$$
\frac{\sum_{i, j=1}^{n}\left(n_{i j}-g_{i j}-\delta_{i j}\right)}{\sum_{i, j=1}^{n} g_{i j}}
$$

where $\delta_{\mathrm{ij}}$, the Kronecker Delta, $=1$ if and only if $\mathrm{i}=\mathrm{j}$ and is 0 otherwise. When the ratio is greater than one, then dominance of indirect effects is said to occur. Analysis of many different models has shown that this ratio is often greater than one, revealing the non-intuitive result that indirect effects have greater contribution than direct effects 
(Salas \& Borrett 2011). Thus, each compartment influences each other, often significantly, by many indirect, non-obvious pathways. The implications of this important result are clear in that each compartment is embedded in and dependent on the rest of the network for its situation, thus calling for a true systems approach to understand such things as feedback and distributed control in the network.

In this particular network the direct and indirect flows are about equal, with slightly more direct. Therefore, the ratio of indirect to direct is slightly less than one $(\mathrm{i} / \mathrm{d}=$ 0.913). Still, the Finn Cycling Index (Finn 1976) demonstrates that over $9 \%$ of the flow is cycled $(\mathrm{FCI}=0.092)$. This is because of the total system throughflow, the boundary flow is 11819 , first passage flow is 15991 and cycled flow is 2816 .

\subsubsection{Network homogenization}

The homogenization property yields a comparison of resource distribution between the direct and integral flow intensity matrices (Fath \& Patten 1999b; Borrett \& Salas 2010). Due to the contribution of indirect pathways, it was observed that flow in the integral matrix was more evenly distributed than that in the direct matrix. A statistical comparison of resources distribution can be made by calculating the coefficient of variation of each of the two matrices. For example, the coefficient of variation of the direct flow intensity matrix $\mathbf{G}$ is given by:

$$
C V(G)=\frac{\sum_{j=1}^{n} \sum_{i=1}^{n}\left(\bar{g}_{i j}-g_{i j}\right)^{2}}{(n-1) \bar{g}}
$$

Network homogenization occurs when the coefficient of variation of $\mathrm{N}$ is less than the coefficient of variation of $\mathbf{G}$ because this says that the network flow is more evenly distributed in the integral matrix. The test statistic employed here looks at whether or not the ratio $\mathrm{CV}(\mathbf{G}) / \mathrm{CV}(\mathbf{N})$ exceeds one. For this ecosystem the homogenization ratio is 1.875 . The interpretation again is clear that the view of flow in ecosystems is not as discrete as it appears because in fact the material is well-mixed (i.e., homogenized) and has traveled through and continues to travel through many, if not, most parts of the system.

\subsubsection{Network mutualism}

Turning now to the utility analysis, the net flow, utility matrix, D, can be used to determine quantitatively and qualitatively the relations between any two components in the network such as predation, mutualism, or competition (Patten 1991, 1992; Fath \& Patten 1998; Fath 2007). Entries in the direct utility matrix, $\mathbf{D}$, or integral utility matrix, $U$, can be positive or negative $\left(-1 \leq d_{i j}, u_{i j}<1\right)$. The elements of $\mathbf{D}$ represent the direct relation between that $(i, j)$ pairing; for the example in Figure 1, this produces the following:

$$
\begin{aligned}
D & =\left[\begin{array}{ccccc}
0 & -\frac{f_{12}}{T_{1}} & 0 & 0 & 0 \\
\frac{f_{21}}{T_{2}} & 0 & -\frac{f_{23}}{T_{2}} & -\frac{f_{24}}{T_{2}} & \frac{f_{25}}{T_{2}} \\
0 & \frac{f_{32}}{T_{3}} & 0 & -\frac{f_{34}}{T_{3}} & 0 \\
& \frac{f_{42}}{T_{4}} & \frac{f_{43}}{T_{4}} & 0 & -\frac{f_{45}}{T_{4}} \\
0 & -\frac{f_{52}}{T_{5}} & 0 & \frac{f_{54}}{T_{5}} & 0 \\
0 & & 0.1837 & 0.0145 \\
0 & -0.7941 & 0 & 0 & 0 \\
0.7734 & 0 & -0.3139 & -0.1834 \\
0 & 0.69261 & 0 & -0.0144 & 0 \\
0 & 0.8846 & 0.0315 & 0 & -0.1552 \\
0 & -0.4514 & 0 & 1.0000 & 0
\end{array}\right]
\end{aligned}
$$

The direct matrix $\mathbf{D}$, being zero-sum, always has the same number of positive and negative signs.

$$
\operatorname{sgn}(D)=\left[\begin{array}{ccccc}
0 & - & 0 & 0 & 0 \\
+ & 0 & - & - & + \\
0 & + & 0 & - & 0 \\
0 & + & + & 0 & - \\
0 & - & 0 & + & 0
\end{array}\right]
$$

The elements of $\mathbf{U}$ provide the integral, system-determined relations. There is one caveat that must be mentioned and that is that integral matrix, contributing indirect flows, makes sense in light of the power series converging. One test that has been proposed for this is based on the eigenvalues of the D matrix. It has been proven that if the absolute value of the largest eigenvalue is less than one, then convergence is guaranteed. It turns out that for the Cone Spring ecosystem, the absolute value of the largest eigenvalue is slightly more than one at 1.0156 . It is still an open research question as to interpretation and alternative approaches. For this example, which is didactic in nature, I will proceed with the integral matrix (which is still calculable from matrix inversion) nonetheless. Therefore, continuing the example, we get the following integral utility matrix and relations between compartments: 
$U=\left[\begin{array}{ccccc}0.6894 & -0.4016 & 0.1279 & 0.0572 & -0.0147 \\ 0.3912 & 0.5058 & -0.1610 & -0.072 & 0.0185 \\ 0.2662 & 0.3441 & 0.8900 & -0.0615 & 0.0145 \\ 0.3305 & 0.4273 & -0.1089 & 0.8044 & -0.1186 \\ 0.1540 & 0.1991 & -0.0362 & 0.8370 & 0.8730\end{array}\right]$

$\operatorname{sgn}(U)=\left[\begin{array}{lllll}+ & - & + & + & - \\ + & + & - & - & + \\ + & + & + & - & + \\ + & + & - & + & - \\ + & + & - & + & +\end{array}\right]$

Unlike, the direct relations, this is not zero-sum. Instead, we see that there are 17 positive signs (including the diagonal) and 8 negatives signs. If there are a greater number of positive signs than negative signs in the integral utility matrix, then network mutualism is said to occur. Here, the ratio is 2.125 . Network mutualism reveals the preponderance of positive mutualistic relations in the system. Specifically, here, we can identify 3 cases of indirect mutualism and 7 of exploitation (Table 4). There are no competition relations in this network.

Table 4. Direct and integral relations in sample network from Figure 1

\begin{tabular}{|l|l|}
\hline \multicolumn{1}{|c|}{ Direct } & \multicolumn{1}{|c|}{ Integral } \\
\hline$\left(\mathrm{sd}_{21}, \mathrm{sd}_{12}\right)=(+,-) \rightarrow$ exploitation & $\left(\mathrm{su}_{21}, \mathrm{su}_{12}\right)=(+,-) \rightarrow$ exploitation \\
\hline$\left(\mathrm{sd}_{31}, \mathrm{sd}_{13}\right)=(0,0) \rightarrow$ neutralism & $\left(\mathrm{su}_{31}, \mathrm{su}_{13}\right)=(+,+) \rightarrow$ mutualism \\
\hline$\left(\mathrm{sd}_{41}, \mathrm{sd}_{14}\right)=(0,0) \rightarrow$ neutralism & $\left(\mathrm{su}_{41}, \mathrm{su}_{14}\right)=(+,+) \rightarrow$ mutualism \\
\hline$\left(\mathrm{sd}_{51}, \mathrm{sd}_{15}\right)=(0,0) \rightarrow$ neutralism & $\left(\mathrm{su}_{51}, \mathrm{su}_{15}\right)=(+,-) \rightarrow$ exploitation \\
\hline$\left(\mathrm{sd}_{32}, \mathrm{sd}_{23}\right)=(+,-) \rightarrow$ exploitation & $\left(\mathrm{su}_{32}, \mathrm{su}_{23}\right)=(+,-) \rightarrow$ exploitation \\
\hline$\left(\mathrm{sd}_{42}, \mathrm{sd}_{24}\right)=(+,-) \rightarrow$ exploitation & $\left(\mathrm{su}_{42}, \mathrm{su}_{24}\right)=(+,-) \rightarrow$ exploitation \\
\hline$\left(\mathrm{sd}_{52}, \mathrm{sd}_{25}\right)=(-,+) \rightarrow$ exploited & $\left(\mathrm{su}_{52}, \mathrm{su}_{25}\right)=(+,+) \rightarrow$ mutualism \\
\hline$\left(\mathrm{sd}_{43}, \mathrm{sd}_{34}\right)=(+,-) \rightarrow$ exploitation & $\left(\mathrm{su}_{43}, \mathrm{su}_{34}\right)=(-,+) \rightarrow$ exploited \\
\hline$\left(\mathrm{sd}_{53}, \mathrm{sd}_{35}\right)=(0,0) \rightarrow$ neutralism & $\left(\mathrm{su}_{53}, \mathrm{su}_{35}\right)=(-,+) \rightarrow$ exploited \\
\hline$\left(\mathrm{sd}_{54}, \mathrm{sd}_{45}\right)=(+,-) \rightarrow$ exploitation & $\left(\mathrm{su}_{54}, \mathrm{su}_{45}\right)=(+,-) \rightarrow$ exploitation \\
\hline
\end{tabular}

\subsubsection{Environ Analysis}

The last property mentioned here is the signature property, the quantitative environ, both in the input and output orientation (Patten 1981). Since each compartment has two distinct environs there are in fact $2 \mathrm{n}$ environs in total. The output environ, $\mathbf{E}$, for the $\mathrm{i}^{\text {th }}$ node is calculated as:
$E=(G-I) \hat{N}_{i}$

where $\hat{N}_{i}$ is the diagonalized matrix of the $i^{\text {th }}$ column of $\mathbf{N}$. When assembled, the result is the output oriented flow from each compartment to each other compartment in the system and across the system boundary. Input environs are calculated as:

$E^{\prime}=\hat{N}_{i}^{\prime}\left(G^{\prime}-I\right)$

where, $\mathrm{g}_{\mathrm{ij}}^{\prime}=\mathrm{f}_{\mathrm{ij}} / \mathrm{T}_{\mathrm{i}}$, and $\mathrm{N}^{\prime}=\left(\mathrm{I}-\mathrm{G}^{\prime}\right)^{-1}$. These results comprise the foundation of Network Environ Analysis since they allow for the quantification of all within system interactions, both direct and indirect, on a compartment-by-compartment basis.

\section{Conclusions}

The daunting question of how to know anything if everything is connected to everything else does not have a single answer. The reductionist approach, to ignore the "everything else", omits too many factors which ultimately are important for the entities behavior within the system. By extending the boundary to include additional entities, one gets a better picture of the interacting system. Network environ analysis is one approach to investigate those within system connections and reveal new insight and understanding. In particular, a series of "network properties" such as indirect effects ratio, homogenization, and mutualism have been observed using this analysis, which consider the role of each entity embedded in a larger system. A practical objective of ecological network analysis in general, and environ analysis in particular, is to trace material and energy flow-storage through the complex network of system interactions. This has been a fruitful way of holistically investigating an organism and "everything else" in the ecosystem and has application to other flow networks.

\section{References}

Bascompte J., Jordano P., Melián C. J. \& Olesen J. M., 2003, The nested assembly of plant-animal mutualistic networks, Proc. Natl. Acad. Sci. USA. 100(16): 9383-9387.

Bata S. A, Borrett S. R., Patten B. C., Whipple S. J., Schramski J. R. \& Gattie D. K, 2007, Equivalence of throughflow- and storage-based environs, Ecol. Modell. 206: 400-406.

Borrett S. R. \& Salas A. K., 2010, Evidence for resource homogenization in 50 trophic ecosystem networks, Ecol. Modell. 221: 1710-1716. 
Dame R. F. \& Patten B. C., 1981, Analysis of energy flows in an intertidal oyster reef, Marine Ecol. Progr. Series 5: $115-124$.

Christian R. R. \& Luczkovich J. J., 1999, Organizing and understanding a winter's seagrass foodweb network through effective trophic levels, Ecol. Modell. 117: 99-124.

Dunne J. A., Williams R. J. \& Martinez N. D., 2002, Foodweb structure and network theory: the role of connectance and size, Proc. Natl. Acad. Sci. U.S.A. 99: 12917-12922.

Dunne J. A., Williams R. J. \& Martinez N. D., 2004, Network structure and robustness of marine food webs, Mar. Ecol. Prog. Series 273: 291-302.

Fath B. D., 2007, Network Mutualism: Positive community level relations in ecosystems, Ecol. Modell. 208: $56-67$.

Fath B. D. \& Patten B. C., 1998, Network synergism: emergence of positive relations in ecological systems, Ecol. Modell. 107: 127-143.

Fath B. D. \& Patten B. C., 1999a, Review of the Foundations of Network Environ Analysis, Ecosystems 2: 167-179.

Fath B. D. \& Patten B. C., 1999b, Quantification of resource homogenization using network flow analysis, Ecol. Modell. 123: 193-205.

Fath B. D, Patten B. C. \& Choi J. S., 2001, Complementarity of ecological goal functions, J. Theor. Biol. 208(4): 493-506.

Finn J. T., 1976, Measures of ecosystem structure and function derived from analysis of flows, J. Theor. Biol. 56: $363-380$.

Halnes G., Fath B. D. \& Liljenström H., 2007, The modified niche model: Including a detritus compartment in simple structural food web models, Ecol. Modell. 208: 9-16.

Higashi M. \& Patten B. C., 1986, Further aspects of the analysis of indirect effects in ecosystems, Ecol. Modell. 31: 69-77.

Higashi M. \& Patten B. C., 1989, Dominance of indirect causality in ecosystems, Am. Nat. 133: 288-302.

Higashi M, Patten B. C. \& Burns T. P., 1993, Network trophic dynamics: the modes of energy utilization in ecosystems, Ecol. Modell. 66: 1-42.

Jordan F., 2009, Keystone species and food webs, Phil. Trans. Roy. Soc. London, series B, 364: 1733-1741.

Jordan F., Liu W. \& Mike A., 2009, Trophic field overlap: a new approach to quantify keystone species, Ecol. Modell. 220: 2899-2907.

Jørgensen S. E., Fath B. D., Bastianoni S., Marques J. C., Müller F., Nielsen S. N., Patten B. C., Tiezzi E. \& Ul- anowicz R. E., 2007, Systems Ecology: A new perspective, Elsevier, Amsterdam.

Kazanci C., 2007, EcoNet: A new software for ecological modeling, simulation and network analysis, Ecol. Modell. 208: 3-8.

Maelzer D. A., 1965, A discussion of components of environment in ecology, J. Theor. Biol. 8: 141-162.

Mason H. L. \& Langenheim J. H., 1957, Language Analysis and the Concept "Environment", Ecology 38: 325340.

Odum E. P., 1953, Fundamentals of Ecology, Saunders, Philadelphia.

Olesen J. M., Bascompte J., Dupont Y. L. \& Jordano P., 2007, The modularity of pollination networks, Proc. Natl. Acad. Sci. USA 104(50): 19891-19896.

Ortiz M., Levins R., Campos L., Berrios F., Campos F., Jordan F., Hermosillo B., Gonzalez J. \& Rodriguez F., 2013, Identifying keystone trophic groups in benthic ecosystems: implications for fisheries management, Ecol. Ind. 25: 133-140.

Patten B. C., 1978, Systems approach to the concept of environment, Ohio J. Sci. 78: 206-222.

Patten B. C., 1981, Environs: the superniches of ecosystems, Am. Zool. 21: 845-852.

Patten B. C., 1982, Environs: relativistic elementary particles or ecology, Am. Nat. 119: 179-219.

Patten B. C., 1991, Network ecology: indirect determination of the life-environment relationship in ecosystems, [in:] M. Higashi, T. P. Burns (eds.), Theoretical Ecosystem Ecology: The Network Perspective, Cambridge University Press, London: 288-351.

Patten B. C., 1992, Energy, emergy and environs, Ecol. Modell. 62: 29-69.

Prigogine I., 1980, From Being to Becoming: Time and complexity in the physical sciences, W.H. Freeman Press, New York.

Salas A. K. \& Borrett S. R., 2011, Evidence for the dominance of indirect effects in 50 trophic ecosystem networks, Ecol. Modell. 22: 1192-1204.

Tilly L. J., 1968, The structure and dynamics of Cone Spring, Ecol. Monogr. 38: 169-197.

Ulanowicz R. E., 2004, Some steps toward a central theory of ecosystem dynamics, Ecol. Questions 5: 23-32.

Ulrich W., 2009, Ecological interaction networks: prospects and pitfalls, Ecol. Questions 11: 17-25.

Whipple S. J. \& Patten B. C., 1993, The problem of nontrophic processes in trophic ecology: towards a network unfolding solution, J. Theor. Biol. 163: 393-411. 
